\title{
Validade Preditiva de Instrumentos Psicológicos Usados na Avaliação Psicológica de Condutores ${ }^{1}$
}

\author{
Fábio Henrique Vieira de Cristo e Silva² \\ Universidade de Brasília \\ João Carlos Alchieri \\ Universidade Federal do Rio Grande do Norte
}

\begin{abstract}
RESUMO - Este estudo analisou a possibilidade de prever infrações de trânsito cometidas por motoristas profissionais a partir dos resultados dos testes psicológicos aplicados no processo de habilitação. Coletaram-se os dados de 68 condutores que exercem atividade remunerada em dois momentos, o primeiro, na aquisição da habilitação, e, o segundo, cinco anos depois, na renovação. As análises não demonstraram diferenças significativas nos escores médios dos testes entre os grupos de motoristas com e sem registro de infração. Também não foram evidenciadas correlações significativas entre os escores dos testes e as pontuações das infrações. Concluiu-se que altos ou baixos escores nos diversos instrumentos não são critérios capazes de definir se um motorista cometerá mais ou menos atos infracionais.
\end{abstract}

Palavras-chave: avaliação psicológica de condutores; validade preditiva; infração de trânsito; testes psicológicos; psicologia do trânsito.

\section{Predictive Validity of Psychological Instruments Used in Psychological Assessment of Drivers}

\begin{abstract}
This study analyzed the possibility to predict traffic infractions committed by professional drivers from test results obtained during the psychological assessment procedure when applying for a license. Data was collected from 68 professional drivers on two separate occasions: upon the acquisition of the license, and five years later, upon license renewal. The analysis did not demonstrate meaningful differences in the average test scores between the groups of drivers with and without a record of infraction. Also no meaningful correlations were evidenced between the test scores and the points attributed to the infractions. It was concluded that neither high nor low scores on the several instruments constitute criteria capable to define whether a driver will commit more or less infractional acts.
\end{abstract}

Keywords: psychological assessment of drivers; predictive validity; traffic infraction; psychological tests; traffic psychology.

O trânsito é considerado atualmente uma problemática das mais importantes do século XXI em função dos altos custos sociais e econômicos que geram, além dos sofrimentos incontáveis para vítimas e familiares decorrentes, principalmente, dos acidentes (IPEA, DENATRAN \& ANTP, 2006; Ministério da Saúde, 2007; OMS, 2009). Os sinistros automobilísticos começaram a se intensificar no Brasil na década de 1940 com a expansão do uso do automóvel, gerando preocupação para as autoridades, que buscaram desenvolver e implementar medidas junto aos diversos campos de conhecimento, como a psicologia (Antipoff, 1956). Uma das estratégias adotadas no Brasil foi a de restringir o acesso

1 Este trabalho foi derivado de dissertação defendida na UFRN, pelo primeiro autor (Silva, 2008). Agradecemos ao apoio financeiro do CNPq por meio de bolsa de mestrado, à Lílian Meire de Oliveira, Célia Cristina Aragão, Thiago Paulinho, Maria Cristina Vieira de Cristo e Silva e Marcelo Eduardo Vieira de Cristo e Silva pelo apoio técnico recebido no desenvolvimento do trabalho; aos professores Lívia de Oliveira Borges e Hartmut Günther pelas reflexões à época da defesa e aos dois pareceristas anônimos pelos comentários úteis na versão preliminar deste artigo. Apoio: $\mathrm{CNPq}$

2 Endereço para contato e correspondência: Universidade de Brasília, Campus Darcy Ribeiro, Instituto Central de Ciências Sul, Instituto de Psicologia, Laboratório de Psicologia Ambiental. Brasília, DF. CEP 70900-100.E-mail: fabiodecristo@gmail.com das pessoas propensas a se envolver em acidentes de trânsito ao volante por meio da avaliação psicológica de condutores. O marco inicial desta atividade no âmbito rodoviário foi o Decreto-lei $\mathrm{n}^{\circ} 9.545$, de 5 de agosto de 1946, em vigor em 1951, que caracterizou o exame psicotécnico para a aquisição da Carteira Nacional de Habilitação (CNH), sendo aplicado à critério de uma junta médica e sem caráter eliminatório. Vários trabalhos versam sobre o desenvolvimento da psicologia do trânsito em outros países (Blasco, 1994; Nagatsuka, 1989; Tortosa \& Montoro, 2002).

O código de trânsito atual define, de maneira geral, que o processo de avaliação psicológica é uma etapa preliminar, obrigatória, eliminatória e complementar para todos os candidatos à obtenção da habilitação, assim como na renovação desse documento no caso dos motoristas que trabalham exercendo atividade remunerada conduzindo veículos (Brasil, 2002). Nesse contexto, o objetivo da avaliação psicológica é o de verificar as condições psicológicas mínimas dos indivíduos para dirigir (p.ex., atenção, inteligência, personalidade) a fim de identificar se eles são capazes ou não de dirigir sem perigo para a própria segurança e de terceiros (Côrtes, 1952; Lamounier \& Rueda, 2005). Em que pese essas exigências, há muito se discute sobre a efetiva colaboração da avaliação psicológica de condutores na promoção da segurança, razão 
principal de sua implementação e manutenção no processo de habilitação há mais de 50 anos. Mas, afinal, a avaliação psicológica contribui ou não para a segurança no trânsito? Nesse artigo, são apresentados os resultados de uma pesquisa sobre este questionamento.

\section{As diferenças individuais no estudo dos acidentes e infrações de trânsito}

A segurança no trânsito, em geral, está fortemente associada ao envolvimento em acidentes automobilísticos. A psicologia, por sua vez, tem contribuído para aprofundar os conhecimentos sobre os aspectos humanos no trânsito, dentre eles, as diferenças individuais. Os psicólogos envolvidos nesta tarefa iniciaram os estudos por meio da seleção de motoristas profissionais e se baseiam na suposição de que alguns motoristas são mais propensos a se envolverem em acidentes do que outros (Groeger \& Rothengatter, 1998; Rothengatter, 1997, 2002). Nesse sentido, pesquisas têm sido desenvolvidos em diversos países para tentar predizer o envolvimento dos motoristas em acidentes. Groeger (2003), após revisar diversos estudos para identificar até que ponto os testes psicológicos predizem segurança no trânsito, concluiu que poucos mostraram relações consistentes. Este autor analisou artigos sobre tempo de reação e coordenação motora, atenção, inteligência, personalidade, estilo perceptivo e julgamento.

No Brasil, desde a década de 1950 observam-se poucas pesquisas sobre os testes psicológicos e a segurança no trânsito (Silva \& Alchieri, 2007, 2008). Vieira, Amorim e Carvalho (1956) apresentaram os primeiros resultados de exames de motoristas realizados por meio dos testes de Atenção Difusa, Tacodômetro, Visão Noturna e Ofuscamento. Os autores concluíram que 5,56\% dos motoristas causadores de acidentes foram reprovados nos testes de habilidade.

Na tentativa de diferenciar grupos de motoristas, Rozestraten (1990) investigou a validade de critério de diversos instrumentos psicológicos em um grupo de 20 motoristas não acidentados e outro de pluri-acidentados. Foram avaliadas as seguintes habilidades: atenção difusa, atenção concentrada (Teste de Cambraia), capacidade visual (Teste de Aptidão para Motorista Militar), tempo de reação visual seletiva e auditivo seletivo, coordenação visomotora (Reprodução de Figuras de Freitas), habilidade motora bimanual (Teste de Discos de Walther), estilo perceptivo dependência-independência de campo (Group Embedded Figures Test - GEFT), orientação espacial (Teste dos Três Labirintos), interesses (Kuder) e inteligência não-verbal (INV-C). Os resultados não indicaram a existência de características que diferenciassem os dois grupos.

Grisci (1991), por sua vez, investigou a relação entre acidentes de trânsito e as variáveis agressividade, atuação (acting-out) e culpa no teste Gestáltico Visomotor de Bender. Participaram da pesquisa 60 motoristas profissionais de uma empresa. Os resultados apontaram que o grupo com histórico de acidentes apresentou um nível significativamente maior de agressividade e atuação em relação ao grupo sem histórico. Aquele grupo apresentou também indicadores de agressividade em maior escala, dificuldade no controle dos impulsos agressivos em relação a si e ao meio-ambiente, bem como a dificuldade em relação a padrões e limites pré-estabelecidos quanto às leis de trânsito e às normas de segurança. Hernandez e Cruz (2001) também usaram o teste de Bender para avaliar 60 motoristas profissionais divididos em grupos com histórico de acidentes e sem histórico ou com pouca freqüência de acidentes. Dos sete sinais de agressão, representados pelos indicadores emocionais, apenas três tiveram diferenças significativas (repasse, pressão do lápis e amontoamento-superposição).

Em função dos resultados apresentados, identificam-se limitações e problemas de operacionalização de indicadores de segurança. Todavia, Groeger (2003) argumenta que, embora existam dificuldades com o risco de envolvimento em acidentes e o envolvimento em acidentes como medida para a segurança (e.g. ao esquecimento dos indivíduos e/ou dos subregistros dessas ocorrências), elas continuam sendo medidas plausíveis.

Outro critério bastante usado para medir segurança no trânsito é a ocorrência de infrações às normas de circulação, consideradas condutas arriscadas; isto porque, uma parcela dos acidentes geralmente é precedida por alguma infração de trânsito (Clark \& Engelmann, 2001; Marín \& Queiroz, 2000). Nesse sentido, existem evidências de que a maior indulgência a comportamentos transgressores às normas de trânsito é acompanhada pela maior probabilidade de infringi-las, e assim de ocorrer acidentes (Moyano Díaz, 1999). O registro de infrações, por sua vez, também é uma medida bastante controvertida, pois nem sempre tais ações são registradas pelas autoridades, seja pela ausência de fiscalização, falta de equipamentos ou mesmo pelas habilidades/estratégias usadas pelos motoristas para burlar as leis (Günther, 2009).

Apesar disso, alguns estudos buscaram relacionar os testes psicológicos e o envolvimento em infrações, seja por meio de auto-relato dos sujeitos ou pelo acesso aos registros dos órgãos de trânsito. Duarte (1999) pesquisou um instrumento de atenção concentrada (AC), o Toulouse-Pierón, e dois instrumentos de personalidade para verificação da validade preditiva em relação aos comportamentos de 182 motoristas. O registro das infrações foi feito pelo Departamento de Trânsito, sendo liberado o acesso ao estudo. Os resultados não evidenciaram diferenças significativas entre motoristas infratores e não infratores no AC, nem correlações entre os resultados do Bender projetivo e os comportamentos infratores; no Inventário Fatorial de Personalidade (IFP), as únicas correlações significativas ocorreram entre o número total de infrações e os fatores assistência e deferência.

Ávila e Benczik (2005) também buscaram avaliar habilidades e personalidade, por meio de estudo de caso único de um motorista profissional infrator que se envolveu em três acidentes. Além da entrevista, foram utilizados os testes AC, R-1 e PMK (formato reduzido). No teste de atenção concentrada, o candidato apresentou o nível de atenção dentro da média esperada para sua escolaridade. No nível mental, apresentou bons índices para solucionar os problemas. No PMK, evidenciaram-se alterações no Desvio Secundário Sagital (DSS); traçado disrítmico em todas as folhas e resultado 
inadequado no DPS; traços disrítmicos, no sentido específico das chamadas Lesões Cerebrais Mínimas. O motorista foi diagnosticado como portador do Transtorno do Déficit de Atenção e Hiperatividade (TDAH) do tipo combinado, sugerindo as autoras que este aspecto estaria relacionado às infrações e acidentes com o motorista.

Frasson e Souza (2002) desenvolveram estudo sobre a personalidade de 10 motoristas que tiveram o direito de dirigir suspenso, utilizando o Rorschach e a Escala Diagnóstica Adaptativa Operacionalizada (EDAO). Os instrumentos sinalizaram dificuldades afetivo-relacionais (distanciamento nas relações interpessoais e desvalorização do outro) e sócio-cultural (menor consciência da responsabilidade sobre os atos e carência de limites; predomínio de relações insatisfatórias com os pais, possibilitando o desencadeamento de dificuldades com a autoridade; e interferência da ansiedade, produzindo distúrbio do sono e da alimentação).

Em outro estudo, Lamounier e Villemor-Amaral (2006) também buscaram evidências de validade para o método de Rorschach (Sistema Compreensivo de Exner). As autoras compararam os indicadores de controle de impulsos, afetividade, agressividade e adequação às normas. Participaram 42 condutores, divididos em dois grupos (21 infratores de trânsito e 21 não infratores). Os resultados mostraram diferenças estatisticamente significativas nos seguintes indicadores do Rorschach: AdjD, $\mathrm{Xu} \%, \mathrm{AG}$ e FC:CF+C $\mathrm{C}^{3}$. Conclui-se que o teste é sensível para identificar características psicológicas de indivíduos que poderiam envolver-se em acidentes.

Recentemente, Bartholomeu (2008) analisou as relações entre traços de personalidade, medidos pelo modelo dos cinco grandes fatores, e os comportamentos de risco no trânsito, avaliado por meio de uma lista com 148 condutas de risco elaborada com base no código de trânsito. Participaram 74 estudantes universitários, a maioria com habilitação. De acordo com os resultados, três condutas de risco se correlacionaram com o fator Socialização, seis condutas com o fator Extroversão, cinco com o fator Escrupulosidade, 32 com o fator Neuroticismo e $11 \mathrm{com}$ o fator Abertura. Das 148 condutas de risco, 57 se relacionaram aos fatores de personalidade avaliados. Em todos os traços investigados foram identificadas associações com comportamentos de risco que se contrapõem aos comportamentos que seriam esperados. Em função disso, o autor sugere que, possivelmente, a própria situação de trânsito produza comportamentos inesperados, não associados às características mais estáveis dos sujeitos.

Conforme os estudos descritos anteriormente, evidencia-se que diferenciar motoristas acidentados de não acidentados, infratores e não infratores, motoristas que adotam ou não condutas arriscadas são, em geral, contraditórios ou parciais, variando em função da medida psicológica aplicada, do critério de segurança e do respectivo tipo de medida, assim como do delineamento metodológico.

3 Esses indicadores significam: controle e tolerância ao estresse (AdjD), capacidade de adequação e percepção da realidade ( $X u \%)$, tendência de manter comportamentos hostis em relação aos demais (AG), boa capacidade de adaptação afetiva (FC), afetividade instável e pouco adaptável (CF), impulsividade associada à falta de adaptação (C). Esses três últimos indicadores são considerados em termos de proporção.

\section{Problemas relacionados à formação profissional, ao processo de testagem e aos parâmetros psicométricos dos instrumentos}

Em geral, os problemas se relacionam às propriedades fundamentais dos instrumentos psicológicos, como a validade, a padronização e a normatização (CFP, 2003; Pasquali, 2001) e ao processo de testagem, sendo algumas condutas, neste caso, consideradas faltas passíveis de punição, conforme o código de ética do psicólogo. Especificamente, a dificuldade de encontrar evidências sobre a relação entre testes psicológicos e segurança no trânsito reside nos seguintes aspectos: a) formação e/ou capacitação profissional inadequada/insuficiente para o exercício da atividade (Rozestraten, 1982; Sbardelini, 1990), b) problemas de validade da medida psicológica utilizada (Groeger, 2003; Silva \& Alchieri, 2007, 2008), c) má qualidade do processo de avaliação psicológica, como, por exemplo, o uso de espaços inapropriados para a aplicação, as simplificações e os erros no uso dos testes, instrumentos copiados e o estabelecimento de critérios menos rigorosos para alguns candidatos à habilitação (Campos, 1973; CFP, 2006; Méa \& Ilha, 2003; Quintela, 1977). Não obstante, ressalta-se que é dever fundamental dos psicólogos a prestação de serviços de qualidade, em condições de trabalho apropriadas, zelando o material privativo do psicólogo (p.ex., guardar adequadamente os testes), sendo ainda vedada a emissão de documentos sem fundamentação e qualidade técnico-científica (CFP, 2005).

Parte desses problemas possui raízes históricas. Alchieri e Stroeher (2002) ao analisarem o desenvolvimento da psicologia do trânsito brasileira, concluíram que os psicólogos ainda não conseguiram responder satisfatoriamente o que eles observam nos testes que caracteriza uma indicação ou não à habilitação. Isso tem favorecido a adoção de critérios aleatórios e particularizados de avaliação do candidato à habilitação. Em outro estudo, Alchieri e Stroeher (2003) identificarem mais de 1.000 indicadores apontados pelos psicólogos para classificar um indivíduo apto ou não nos testes de habilidades, 402 indicadores nos testes de inteligência e 2.056 indicadores nos testes de personalidade. Lamounier e Rueda (2005), por outro lado, encontraram evidências de concordância entre as avaliações de 110 candidatos à obtenção da habilitação no PMK. Das avaliações feitas por eles, houve discordâncias em apenas dois casos.

Diante disso, pergunta-se: como as pesquisas podem ser direcionadas para tentar caracterizar melhor a relação entre testes psicológicos e segurança no trânsito? Recentemente, Silva e Alchieri $(2007,2008)$ realizaram ampla sistematização da produção empírica sobre os estudos de personalidade, habilidades e inteligência com motoristas e concluíram que, em cinco décadas, as pesquisas não têm evidenciado de maneira sistemática e consistente os ganhos efetivos com a segurança no trânsito por meio da avaliação dos condutores. Os autores sugerem algumas diretrizes para futuras pesquisas: a) delineamentos longitudinais e de follow-up, que acompanham por um período de tempo os (futuros) motoristas, b) incremento de ações integradas/parcerias entre a universidade e as instituições responsáveis pelo trânsito e transporte rodoviário, a fim de estudar amostras representa- 
tivas de determinada população de motoristas, c) estudos de validade preditiva que possibilitem identificar em que medida os testes são capazes de oferecer aos psicólogos indicadores de comportamentos futuros dos motoristas. A validade preditiva é um aspecto da validade que busca estabelecer relações entre o desempenho em um teste e outros fatores independentemente observáveis do comportamento, de modo que se possa estabelecer a probabilidade de ocorrência deste em função dos resultados do teste (Anastasi \& Urbina, 2000).

Dos poucos estudos anteriormente realizados, não foram encontradas contribuições significativas que estabelecem empiricamente relações entre as medidas psicológicas e medidas do comportamento infrator do motorista (Ávila \& Benczik, 2005; Duarte, 1999; Frasson \& Souza, 2002; Grisci, 1991; Lamounier \& Rueda, 2005; Lamounier \& Villemor-Amaral, 2006). Tentativas nessa direção são sempre prioritárias para o campo da avaliação psicológica de condutores, sem as quais sua eficácia em relação à promoção de segurança no trânsito será sempre questionada. Na perspectiva de investir esforços em direção às lacunas apontadas acima, desenvolveu-se um estudo para tentar identificar a possibilidade de prever a ocorrência de infrações de trânsito a partir dos resultados dos testes psicológicos aplicados no processo de habilitação. A pesquisa consistiu na identificação dos testes e dos escores obtidos, assim como dos pontos na $\mathrm{CNH}$, verificando se os escores médios dos testes dos motoristas com e sem registro de infração são significativamente distintos e se existem relações entre os escores dos testes e a freqüência de infrações. Espera-se contribuir com o aprimoramento da avaliação psicológica em condutores e para o aprofundamento das discussões teórico-metodológicas na área.

\section{Método}

Adequou-se o método a um delineamento follow-up, identificando os resultados dos testes e das infrações dos motoristas no período de cinco anos (no processo de aquisição e renovação da $\mathrm{CNH}$ ), registradas pelas autoridades de trânsito. Contou-se com a colaboração do órgão de trânsito e de uma clínica credenciada que avalia psicologicamente os candidatos à $\mathrm{CNH}$ no Rio Grande do Norte. Ambas as instituições autorizaram o desenvolvimento da pesquisa e disponibilizaram o material para as análises.

\section{Material}

Os materiais coletados e analisados foram: a) os protocolos de testes psicológicos aplicados por psicólogos peritos da clínica credenciada, sendo identificados os pareceres finais nos exames, os construtos avaliados, os nomes dos testes e os escores brutos obtidos pelos indivíduos. Conforme as exigências do Conselho Nacional de Trânsito (CONTRAN, $1998)^{4}$, deveriam ser avaliadas três grandes áreas de con-

4 O presente estudo ocorreu durante a vigência desta resolução. Lembra-se, no entanto, que foi publicado recentemente um novo documento, a Resolução CONTRAN n ${ }^{\circ} 267$, de 15 de fevereiro de 2008, que dispõe sobre o exame de aptidão física e mental, a avaliação psicológica e o credenciamento das entidades públicas e privadas (www.denatran.gov.br). centração de características psicológicas: (1) percepto-reacional, motora e nível mental, (2) equilíbrio psíquico e (3) habilidades específicas; e b) os prontuários com o histórico de infrações de cada participante, sendo registrados dados sócio-demográficos (sexo, escolaridade, estado civil e cidade onde reside) e da habilitação (serviços realizados - se primeira habilitação, renovação e/ou mudança - e pontuação).

Todo o material psicológico analisado na pesquisa foi aplicado por 13 psicólogos peritos em trânsito (seis participaram apenas no primeiro momento, quatro aplicaram apenas no segundo momento e três aplicaram nos dois momentos). Não foi possível identificar o profissional responsável pela aplicação, análise e avaliação de 69 protocolos de testes (pouco mais de $50 \%$ de todo o material analisado nos dois momentos), uma vez que os documentos ou não estavam assinados ou só havia rubrica sem o carimbo, nome e registro profissional. Os exames psicológicos de 2002 foram aplicados em 6 postos, em Natal e Parnamirim, nos meses de janeiro a outubro. Os exames psicológicos de 2007 foram aplicados em 7 postos, também em Natal e Parnamirim, nos meses entre fevereiro e novembro. Ressalta-se que atualmente existem 16 postos de atendimento, seis em Natal e dez no interior.

\section{Participantes}

A população-alvo do estudo foi de motoristas que exerciam atividade remunerada de transporte de bens ou pessoas (motoristas profissionais) de qualquer categoria de habilitação, escolaridade e sexo, que tivessem se submetido a dois processos de avaliação psicológica, sendo o primeiro na ocasião da aquisição da permissão para dirigir, em 2002, e o segundo na renovação e/ou na mudança de categoria de habilitação, em 2007. Os testes psicológicos aplicados antes de 2002 não foram coletados por já terem sido destruídos dos arquivos do órgão de trânsito. O levantamento da população foi autorizado e realizado pelo próprio órgão de trânsito, por meio da empresa terceirizada que gerencia o banco de dados com as informações dos condutores. As listas contendo os dados dos condutores selecionados foram enviadas aos pesquisadores. Foi identificada uma população de 839 condutores de 14 municípios do Rio Grande do Norte que atenderam aos critérios da pesquisa.

A proposta inicial era investigar toda a população identificada; porém isto se mostrou inviável, pois foram encontrados efetivamente 127 protocolos de testes psicológicos aplicados em 2002 nos arquivos do órgão de trânsito. Foram então solicitados 127 protocolos à clínica credenciada, que encontrou apenas 76 protocolos referentes à 2007. Nesse material recebido pelos pesquisadores havia alguns protocolos referentes a 2006, 2008 e outros com motoristas que não constavam na lista enviada. Esses protocolos não foram incluídos nas análises.

A amostra pesquisada, portanto, foi de 68 motoristas do sexo masculino com média de idade de 21,72 anos (DP = $5,24)$. Na escolaridade, 39 motoristas possuem o ensino médio completo/incompleto e 29 possuem o ensino fundamental completo/incompleto. Em relação ao estado civil, 38 são solteiros e 13 são casados/união estável. No que concerne à 
cidade de moradia, a maioria reside em Natal (38) e Parnamirim (15), e nos outros municípios do estado houve uma freqüência menor ou igual a 5 .

Em 2002, 49 candidatos à $\mathrm{CNH}(72 \%)$ foram considerados aptos/aptos com restrição, 17 (25\%) considerados inaptos/inaptos temporários e, em dois casos (3\%), o parecer final não constava no laudo anexado ao protocolo. Em 2007, 62 candidatos à $\mathrm{CNH}(91,2 \%)$ foram considerados aptos, 5 $(7,3 \%)$ considerados inaptos/inaptos temporários e, em um caso $(1,5 \%)$, o parecer final não constava no laudo anexado ao protocolo. A maioria adquiriu a primeira habilitação na categoria $\mathrm{AB}$ (43) e B (15). Ao efetuar os exames psicológicos pela segunda vez, a maioria dos condutores renovou e/ ou mudou sua habilitação para a categoria $\mathrm{AD}$ (45) e D (11). Nas outras categorias (AB, A, B e AE), a freqüência foi igual ou inferior a 4. A amostra, portanto, não pode ser considerada representativa da população pesquisada.

\section{Procedimentos}

A coleta dos resultados dos testes se iniciou em maio de 2007 e encerrou em maio de 2008. Durante esse período foram realizadas três buscas no órgão de trânsito e duas na clínica credenciada. Nos arquivos do órgão de trânsito foram coletados os protocolos de testes de 2002 pelo próprio pesquisador e seus colaboradores, mediante autorização, armazenados em todas as 89 caixas-arquivo existentes. Neste caso, as buscas foram feitas com base em listagens disponibilizadas pelo órgão de trânsito que continham informações de toda a população de motoristas que se adequavam aos critérios da pesquisa. As informações das listagens eram comparadas com as informações dos testes, selecionando-os à medida que os dados do condutor coincidiam.

Foram enfrentadas dificuldades para identificar os testes nas caixas a partir das informações disponíveis (local, dia, mês e ano de realização dos exames), uma vez que as datas do sistema não correspondiam às datas dos arquivos. É oportuno destacar que a busca dos testes psicológicos referentes a 2002 ocorreu no órgão de trânsito em função de que ali se encontravam os arquivos da clínica anteriormente credenciada. Somente a partir de meados de 2003 uma nova clínica foi conveniada para a realização dos exames psicológicos, razão pela qual solicitou-se os exames de 2007.

Os prontuários com as infrações, por sua vez, foram coletados em dois momentos, o primeiro em agosto de 2007, com os protocolos dos condutores encontrados até aquele momento nos arquivos de 2002, e, o segundo, em maio de 2008, com a amostra total de condutores. Esta coleta se mostrou bastante rápida, sendo o material impresso e disponibilizado pelo órgão de trânsito após a solicitação do pesquisador através de ofício. Os dados das infrações foram provenientes de um sistema interligado entre os órgãos fiscalizadores de trânsito. Este sistema disponibiliza informações objetivas para a execução de ações por parte dessas entidades. A partir desses dados realizaram-se as análises pertinentes ao estudo (estatística descritiva, Teste t e correlação de Pearson).

\section{Resultados}

Identificaram-se 17 testes usados no processo de avaliação psicológica em condutores em 2002 e 2007. Conforme a Tabela 1, em 2002, 14 testes foram empregados, sendo os mais freqüentes em cada área: R-1, palográfico, atenção concentada (AC) Suzy Cambraia e TADIM-2. A personalidade foi avaliada apenas por testes projetivos. A atenção concentrada apresentou maior diversidade de testes (cinco) em relação aos outros construtos avaliados. Um teste de atenção difusa não foi aplicado ou anexado junto ao protocolo de testes, embora constasse como aplicado no laudo psicológico (dos 68 testes esperados, tendo em vista serem 68 motoristas). Além disso, 49 instrumentos não foram corrigidos ou analisados: 43 de personalidade, quatro de atenção difusa,

Tabela 1. Áreas, Construtos Avaliados, Testes Usados e Freqüência de Uso - 2002

\begin{tabular}{|c|c|c|c|c|c|c|c|}
\hline \multirow{2}{*}{\multicolumn{2}{|c|}{$\begin{array}{c}\text { Área I } \\
\text { Inteligência }\end{array}$}} & \multicolumn{2}{|c|}{ Área II } & \multicolumn{4}{|l|}{ Área III } \\
\hline & & \multicolumn{2}{|c|}{ Personalidade } & \multicolumn{2}{|l|}{ Atenção Concentrada } & \multicolumn{2}{|c|}{ Atenção Difusa } \\
\hline Teste & $\mathrm{N}$ & Teste & $\mathrm{N}$ & Teste & $\mathrm{N}$ & Teste & $\mathrm{N}$ \\
\hline $\mathrm{R}-1$ & 65 & Palográfico & 36 & Atenção Concentrada (AC) Suzy Cambraia & 33 & TADIM-2 & 29 \\
\hline D-48 & 2 & WZT & 21 & TACOM-B & 16 & TADIM & 26 \\
\hline \multirow[t]{3}{*}{$\begin{array}{l}\text { INV- } \\
\mathrm{C}\end{array}$} & 1 & HTP & 11 & $\mathrm{D}-2$ & 9 & MPM & 12 \\
\hline & & & & AC Toulouse-Piéron & 8 & & \\
\hline & & & & ACRE & 2 & & \\
\hline Total: & 68 & & 68 & & 68 & & 67 \\
\hline
\end{tabular}

Nota: R-1=Teste Não Verbal de Inteligência; D-48=Teste Dominós 48; INV-C=Teste de Inteligência Não Verbal Forma C; WZT=Teste Wartegg; HTP=Teste da Casa, Árvore e Pessoa; TACOM-B=Teste de Atenção Concentrada Forma B; D-2=Teste de Atenção Concentrada D-2; ACRE=Teste de Atenção Concentrada, Rapidez e Exatidão; TADIM e TADIM-2=Teste de Atenção Difusa e Atenção Difusa 2; MPM=Teste Medida da Prontidão Mental. 
Tabela 2. Áreas, Construtos Avaliados, Testes Usados e Freqüência de Uso - 2007

\begin{tabular}{cccccccc}
\hline \multicolumn{2}{c}{ Área I } & \multicolumn{2}{c}{ Área II } & \multicolumn{3}{c}{ Área III } \\
\multicolumn{2}{c}{ Inteligência } & \multicolumn{2}{c}{ Personalidade } & Atenção Concentrada & \multicolumn{2}{c}{ Atenção Difusa } \\
Teste & $\mathrm{N}$ & Testes & $\mathrm{N}$ & Teste & $\mathrm{N}$ & Teste & $\mathrm{N}$ \\
\hline R-1 & 60 & Palográfico & 67 & AC Suzy Cambraia & 55 & TADIM & 50 \\
TRAP-1 & 7 & & & TACOM-B & 7 & TEDIF-1 & 11 \\
& & & & TACOM-A & 5 & TADIM-2 & 6 \\
Total: & 67 & & 67 & & 67 & & 67 \\
\hline
\end{tabular}

Nota: TRAP-1 = Teste de Raciocínio Lógico; TACOM-A e B = Teste de Atenção Concentrada para Motorista forma A e B; TEDIF-1 = Teste de Atenção Difusa 1.

Tabela 3. Número de participantes que fizeram os mesmos Testes em 2002 e 2007.

\begin{tabular}{cccccccc}
\hline Teste inteligência & $\mathrm{N}$ & $\begin{array}{c}\text { Teste persona- } \\
\text { lidade }\end{array}$ & $\mathrm{N}$ & Teste atenção concentrada & $\mathrm{N}$ & $\begin{array}{c}\text { Teste atenção } \\
\text { difusa }\end{array}$ & $\mathrm{N}$ \\
\hline R-1 & 57 & Palográfico & 32 & AC Suzy Cambraia & 28 & TADIM & 20 \\
& & & TACOM - B & 3 & TADIM - 2 & 4 \\
Total: & 57 & & 32 & & 11 & 24 \\
\hline
\end{tabular}

Tabela 4. Estatísticas descritivas dos resultados dos candidatos por teste e por ano.

\begin{tabular}{lllll}
\hline Teste/Ano de Aplicação & N & Variação dos Escores Brutos & Média & Desvio-Padrão \\
\hline R-1 (2002) & 57 & De 9 a 35 pontos & 24,23 & 5,34 \\
R-1 (2007) & 57 & 14 a 37 & 27,21 & 5,35 \\
AC Suzy Cambraia (2002) & 28 & 34 a 120 & 76,75 & 23,94 \\
AC Suzy Cambraia (2007) & 28 & 54 a 134 & 86,07 & 21,85 \\
TACOM - B (2002) & 3 & 77 a 105 & 88,67 & 14,57 \\
TACOM - B (2007) & 3 & 30 a 114 & 72 & 42 \\
TADIM (2002) & 20 & 15 a 50 & 34,80 & 9,90 \\
TADIM (2007) & 20 & 22 a 50 & 38 & 8,27 \\
TADIM-2 (2002) & 4 & 32 a 44 & 37,75 & 5,68 \\
TADIM-2 (2007) & 4 & 36 a 48 & 42,25 & 5,32 \\
\hline
\end{tabular}

um de inteligência e um de atenção concentrada. Dos testes aplicados, cinco não são atualmente indicados para uso na lista do Conselho Federal de Psicologia: D-48, INV-C, WZT, AC Toulouse-Piéron e ACRE.

Conforme a Tabela 2 usou-se nove instrumentos para avaliar os construtos em 2007. Excetuando-se o TADIM-2 que foi o mais usado para avaliar atenção difusa, os testes mais usados em cada área foram os mesmos usados anteriormente. A personalidade foi avaliada apenas pelo palográfico. Em 2007, não foram aplicados ou anexados junto ao protocolo quatro testes, um de cada construto. Isso pode indicar a perda do material ou a não aplicação dos mesmos, embora no laudo constem as aplicações. A quantidade de testes não corrigidos ou analisados também aumentou para 69, sendo um de inteligência e todos os 68 de personalidade.

$\mathrm{O}$ uso de mais de um instrumento para medir os mesmos construtos, evidencia diferenças na composição das baterias de testes nos dois momentos. Dos 17 instrumentos identifi- cados, apenas seis foram aplicados nos dois momentos e nos mesmos sujeitos, conforme a Tabela 3 .

As estatísticas descritivas dos escores brutos dos candidatos, por instrumento e ano, são apresentadas na Tabela 4. Os resultados sugerem que o desempenho dos candidatos aumentou com o tempo. Somente as médias do escores brutos do TACOM-B não aumentou após cinco anos. Os resultados do teste Palográfico não constam pois, conforme dito anteriormente, nenhum deles havia sido analisado em 2007.

Os dados dos prontuários (histórico de infrações) evidenciaram que a maior parte dos motoristas (54) não apresentou registros de infração nos cinco anos, período entre as avaliações psicológicas. Apenas 14 motoristas tiveram registro de infração, sendo eles responsáveis por 29 ocorrências de violações às leis de trânsito: seis motoristas cometeram uma infração, cinco cometeram duas infrações, dois motoristas cometeram três infrações e um cometeu sete infrações de 
Tabela 5. Diferenças das Médias dos Escores brutos Entre Motoristas Infratores e Não Infratores por Teste e Ano de Aplicação.

\begin{tabular}{|c|c|c|c|c|c|c|c|c|c|}
\hline Instrumentos & Grupo & $N$ & $\begin{array}{c}\text { Escores brutos } \\
\text { (Média) }\end{array}$ & $D P$ & Mínimo & Máximo & $\begin{array}{l}\text { Teste t } \\
\text { Student }\end{array}$ & $G L$ & $\mathrm{p}$ \\
\hline \multirow{2}{*}{ AC Suzy Cambraia (2002) } & Infrator & 6 & 72,50 & 27,595 & 38 & 120 & \multirow{2}{*}{$-0,484$} & \multirow{2}{*}{26} & \multirow{2}{*}{0,633} \\
\hline & Não infrator & 22 & 77,91 & 23,428 & 34 & 119 & & & \\
\hline \multirow{2}{*}{ AC Suzy Cambraia (2007) } & Infrator & 6 & 86,17 & 16,005 & 66 & 107 & \multirow{2}{*}{0,012} & \multirow{2}{*}{26} & \multirow{2}{*}{0,991} \\
\hline & Não infrator & 22 & 86,05 & 23,514 & 54 & 134 & & & \\
\hline $\mathrm{R}-1$ & Infrator & 10 & 23,60 & 4,427 & 18 & 30 & \multirow[b]{2}{*}{$-0,407$} & \multirow{2}{*}{55} & \multirow{2}{*}{0,686} \\
\hline$(2002)$ & Não infrator & 47 & 24,36 & 5,542 & 9 & 35 & & & \\
\hline $\mathrm{R}-1$ & Infrator & 10 & 27,20 & 4,417 & 21 & 34 & \multirow[b]{2}{*}{$-0,007$} & \multirow[b]{2}{*}{55} & \multirow[b]{2}{*}{0,995} \\
\hline (2007) & Não infrator & 47 & 27,21 & 5,575 & 14 & 37 & & & \\
\hline \multirow{2}{*}{ TADIM (2002) } & Infrator & 2 & 33,50 & 14,849 & 23 & 44 & \multirow{2}{*}{$-0,191$} & \multirow{2}{*}{18} & \multirow{2}{*}{0,851} \\
\hline & Não infrator & 18 & 34,94 & 9,819 & 15 & 50 & & & \\
\hline \multirow{2}{*}{ TADIM (2007) } & Infrator & 2 & 38,50 & 2,121 & 37 & 40 & \multirow{2}{*}{0,088} & \multirow{2}{*}{18} & \multirow{2}{*}{0,931} \\
\hline & Não infrator & 18 & 37,94 & 8,721 & 22 & 50 & & & \\
\hline
\end{tabular}

trânsito. A pontuação na CNH na amostra variou de 0 a 35, e o valor típico de pontos, a partir da mediana, foi zero. Isso indica que a amostra se caracteriza predominantemente por motoristas sem registros de infração. No grupo com registro de infração a pontuação variou de 3 a 35, com média de $10,79(\mathrm{DP}=7,73)$.

Realizaram-se duas análises para tentar identificar possíveis diferenças nos escores médios dos testes dos motoristas com e sem registro de infração (infrator x não infrator). Não foram incluídos nessas análises os testes Palográfico, TACOM-B e TADIM-2, o primeiro, em função das não correções, e, os últimos, pela pouca quantidade de sujeitos (ver Tabela 3). A primeira análise comparou por teste e ano somente os motoristas com e sem registro de infração que se submeteram ao mesmo teste em 2002 e 2007 (ver Tabela 5).

Conforme a Tabela 5, o Teste $t$ para amostras independentes não indicou diferenças estatisticamente significativas entre os grupos nos instrumentos psicológicos aplicados, tanto em 2002 quanto em 2007, indicando que as características psicológicas dos motoristas sem registro de infração não são melhores ou piores do que aqueles com registro de infração.

$\mathrm{Na}$ segunda tentativa, compararam-se os motoristas com e sem registro de infração que se assemelharam nas características sócio-demográficas (ver Tabela 6). Selecionaram-se 28 motoristas (14 para cada grupo, uma vez que apenas 14 tiveram registro de infração). $\mathrm{O}$ nível de escolaridade foi o critério mais importante, seguido do tipo de habilitação, estado civil e sexo, nesta ordem. Neste caso, os testes usados não eram os mesmos nos dois momentos, conforme a variedade de testes aplicados nos motoristas mostrados anteriormente.

Conforme a Tabela 6 , o Teste $t$ para amostras independentes evidenciou diferenças estatisticamente significativas no caso dos escores obtidos nos instrumentos de avaliação da atenção concentrada em $2002(t=2,21 ; g l=25 ; p=0,037) \mathrm{e}$ da atenção difusa em $2002(t=2,37 ; g l=24 ; p=0,026)$. Esses resultados sugerem que motoristas sem registro de infração possuem maior capacidade de atenção concentrada e difusa do que aqueles com registro de infração, se considerada a avaliação feita em 2002 .

\section{Relações entre infrações e os escores dos testes}

Analisaram-se por meio da correlação de Pearson as relações entre os escores brutos dos testes e a quantidade de pontos perdidos na $\mathrm{CNH}$, devido às infrações cometidas em cinco anos (ver Tabela 7).

De acordo com a Tabela 7 , os resultados não evidenciaram correlações estatisticamente significativas entre os escores brutos dos testes e a quantidade de pontos na $\mathrm{CNH}$ dos motoristas. As correlações positivas e significativas encontradas foram entre os escores brutos dos testes na primeira aplicação e na segunda: AC Suzy Cambraia de 2002 e 2007 ( $r=0,586$; $p=0,001)$, R-1 de 2002 e $2007(r=0,598 ; p=0,001)$ e TADIM de 2002 e $2007(r=0,648 ; p=0,002)$. À medida que os escores dos testes em 2002 aumenta, os escores em 2007 também aumentam, sugerindo uma congruência entre as medidas. O R-1, um teste de inteligência, apresentou em 2002 uma correlação positiva e significativa com o TADIM, um teste de atenção difusa, tanto de 2002 quanto de 2007 ( $r=0,485$; $p=0,048$ e $r=0,675 ; p=0,003$, respectivamente), evidenciando relação entre inteligência e atenção difusa.

\section{Discussão}

A avaliação psicológica dos candidatos à habilitação se constitui, ainda hoje, na principal atividade de grande parte dos psicólogos do trânsito no Brasil. Há mais de 50 anos esta prática psicológica se inseriu no contexto rodoviário com a finalidade de contribuir para a segurança no trânsito, identificando os motoristas mais propensos a se envolverem 
Tabela 6. Diferenças das Médias dos Escores Brutos Entre Motoristas Infratores e Não Infratores com Características Sócio-demográficas Semelhantes

\begin{tabular}{|c|c|c|c|c|c|c|c|c|c|}
\hline Instrumentos & Grupo & $\mathrm{N}$ & $\begin{array}{l}\text { Escores brutos } \\
\text { (Média) }\end{array}$ & DP & Mínimo & Máximo & $\begin{array}{c}\text { Teste } \\
\text { t Student }\end{array}$ & GL & $p$ \\
\hline \multirow[t]{2}{*}{$\begin{array}{l}\text { Atenção concentrada } \\
(2002)\end{array}$} & Infratores & 13 & 96,77 & 85,710 & 38 & 372 & \multirow[b]{2}{*}{$-2,208$} & \multirow[b]{2}{*}{25} & \multirow[b]{2}{*}{0,037} \\
\hline & $\begin{array}{l}\text { Não infra- } \\
\text { tores }\end{array}$ & 14 & 215,21 & 174,750 & 40 & 508 & & & \\
\hline \multirow[t]{2}{*}{$\begin{array}{l}\text { Atenção concentrada } \\
(2007)\end{array}$} & Infratores & 14 & 86,43 & 19,610 & 45 & 121 & \multirow[b]{2}{*}{$-0,405$} & \multirow[b]{2}{*}{26} & \multirow[b]{2}{*}{0,689} \\
\hline & $\begin{array}{l}\text { Não infra- } \\
\text { tores }\end{array}$ & 14 & 89,79 & 24,068 & 54 & 134 & & & \\
\hline \multirow[t]{2}{*}{ Atenção difusa (2002) } & Infratores & 14 & 31,93 & 8,389 & 20 & 44 & \multirow[b]{2}{*}{$-2,370$} & \multirow[b]{2}{*}{24} & \multirow[b]{2}{*}{0,026} \\
\hline & $\begin{array}{l}\text { Não infra- } \\
\text { tores }\end{array}$ & 12 & 39,75 & 8,390 & 21 & 50 & & & \\
\hline \multirow[t]{2}{*}{ Atenção difusa (2007) } & Infratores & 14 & 37,57 & 6,969 & 25 & 50 & \multirow[b]{2}{*}{$-0,787$} & \multirow[b]{2}{*}{26} & \multirow[b]{2}{*}{0,439} \\
\hline & $\begin{array}{l}\text { Não infra- } \\
\text { tores }\end{array}$ & 14 & 39,71 & 7,436 & 28 & 50 & & & \\
\hline \multirow[t]{2}{*}{ Inteligência (2002) } & Infratores & 14 & 25,00 & 4,368 & 18 & 30 & \multirow[b]{2}{*}{0,525} & \multirow[b]{2}{*}{26} & \multirow[b]{2}{*}{0,604} \\
\hline & $\begin{array}{l}\text { Não infra- } \\
\text { tores }\end{array}$ & 14 & 24,00 & 5,630 & 9 & 32 & & & \\
\hline \multirow[t]{2}{*}{ Inteligência (2007) } & Infratores & 14 & 26,50 & 5,050 & 18 & 34 & \multirow[b]{2}{*}{$-1,338$} & \multirow[b]{2}{*}{26} & \multirow[b]{2}{*}{0,193} \\
\hline & $\begin{array}{l}\text { Não infra- } \\
\text { tores }\end{array}$ & 14 & 29,00 & 4,836 & 17 & 33 & & & \\
\hline
\end{tabular}

Tabela 7. Correlações Entre os Instrumentos Psicológicos e o Número de Pontos na Carteira Nacional de Habilitação.

\begin{tabular}{|c|c|c|c|c|c|c|c|c|}
\hline Instrumentos/ano de aplicação & & $\begin{array}{c}\text { AC Suzy } \\
\text { Cambraia } \\
(2002)\end{array}$ & $\begin{array}{c}\text { AC Suzy } \\
\text { Cambraia } \\
(2007)\end{array}$ & $\begin{array}{c}\text { R-1 } \\
(2002)\end{array}$ & $\begin{array}{c}\text { R-1 } \\
(2007)\end{array}$ & $\begin{array}{l}\text { TADIM } \\
(2002)\end{array}$ & $\begin{array}{l}\text { TADIM } \\
(2007)\end{array}$ & $\begin{array}{c}\text { Pontos na } \\
\mathrm{CNH}\end{array}$ \\
\hline \multirow[t]{3}{*}{ AC Suzy Cambraia (2002) } & $\mathrm{r}$ & & 0,586 & 0,286 & 0,355 & 0,706 & 0,711 & 0,006 \\
\hline & $\mathrm{p}$ & & 0,001 & 0,185 & 0,097 & 0,076 & 0,073 & 0,974 \\
\hline & $\mathrm{N}$ & & 28 & 23 & 23 & 7 & 7 & 28 \\
\hline \multirow[t]{3}{*}{ AC Suzy Cambraia (2007) } & $\mathrm{r}$ & & & $-0,015$ & 0,390 & 0,670 & 0,606 & $-0,005$ \\
\hline & $\mathrm{p}$ & & & 0,946 & 0,065 & 0,100 & 0,149 & 0,979 \\
\hline & $\mathrm{N}$ & & & 23 & 23 & 7 & 7 & 28 \\
\hline \multirow[t]{3}{*}{ R-1 (2002) } & $\mathrm{r}$ & & & & 0,598 & 0,485 & 0,675 & 0,021 \\
\hline & $\mathrm{p}$ & & & & 0,000 & 0,048 & 0,003 & 0,879 \\
\hline & $\mathrm{N}$ & & & & 57 & 17 & 17 & 57 \\
\hline \multirow[t]{3}{*}{ R-1 (2007) } & $\mathrm{r}$ & & & & & 0,171 & 0,436 & 0,026 \\
\hline & $\mathrm{p}$ & & & & & 0,513 & 0,080 & 0,850 \\
\hline & $\mathrm{N}$ & & & & & 17 & 17 & 57 \\
\hline \multirow[t]{3}{*}{ TADIM (2002) } & $\mathrm{r}$ & & & & & & 0,648 & $-0,280$ \\
\hline & $\mathrm{p}$ & & & & & & 0,002 & 0,231 \\
\hline & $\mathrm{N}$ & & & & & & 20 & 20 \\
\hline \multirow[t]{3}{*}{ TADIM (2007) } & $\mathrm{r}$ & & & & & & & 0,057 \\
\hline & $\mathrm{p}$ & & & & & & & 0,811 \\
\hline & $\mathrm{N}$ & & & & & & & 20 \\
\hline
\end{tabular}


em acidentes. Contudo, são escassos os estudos empíricos que buscaram evidências sobre a contribuição efetiva da psicologia na segurança por meio da avaliação psicológica (Silva \& Alchieri, 2007, 2008).

Assume-se aqui a importância das infrações como um indicador objetivo de segurança, especialmente quando é por meio delas que os departamentos de trânsito desenvolvem intervenções e/ou políticas. Assim, desenvolveu-se este trabalho para tentar identificar a possibilidade de prever o envolvimento em infrações de trânsito a partir dos resultados dos testes psicológicos aplicados por psicólogos peritos no processo de habilitação de condutores.

O estudo teve a expectativa de investigar toda a população identificada e compatível com os critérios da pesquisa (839 motoristas); todavia, restringiu-se a somente $9 \%$ da população, ou seja, 68 condutores, em função de muitos protocolos de testes não terem sido encontrados. Isso pode ser indício de falha na guarda do material psicológico, o que se configura em infração ética passível de punição (CFP, 2005). A literatura indica outros problemas na avaliação psicológica de condutores que interferem na qualidade do processo avaliativo, por exemplo, condições inadequadas de aplicação e uso dos testes copiados (CFP, 2006; Méa \& Ilha, 2003). Do ponto de vista metodológico, este dado evidencia que desenvolver parcerias com instituições de trânsito não garante a possibilidade de estudar amostras representativas de determinada população de motoristas, conforme sugerem Silva e Alchieri (2007).

Alguns testes psicológicos usados nesta amostra pelos psicólogos são amplamente aplicados para o trânsito no âmbito nacional (ver Alchieri \& Stroeher, 2003; CFP, 2006). Contudo, parte dos instrumentos usados em 2002 não consta atualmente na lista do Sistema de Avaliação de Testes Psicológicos do CFP, como o INV-C, D-48, WZT, ACRE e AC Toulouse-Piéron. Isso indica que eles não possuem as garantias mínimas necessárias para serem reconhecidos como testes psicológicos e possam ser utilizados pelos profissionais da psicologia (CFP, 2003).

A coleta dos protocolos evidenciou que não foi possível identificar o profissional responsável pela aplicação em vários casos (pouco mais de 50\%), pois os documentos não estavam assinados ou constavam apenas rubricas sem o carimbo com nome e registro no conselho. Também não foram aplicados ou não foram anexados alguns testes psicológicos, indicando possível perda do material ou a sua não aplicação. Além disso, muitos testes não foram corrigidos ou analisados, notadamente os testes projetivos. Considerando esses dados e os pareceres finais dos candidatos nos exames (e.g. em 2007, apenas cinco motoristas da amostra foram considerados inaptos/inaptos temporários), evidencia-se que os candidatos podem estar sendo aprovados sem que tenham sido avaliados plenamente, especialmente a personalidade. Um problema semelhante foi apontado por Quintela (1977), quando identificou a aplicação indevida e abreviada do PMK, comprometendo a validade deste instrumento. Da mesma forma que os problemas de guarda do material, a não aplicação ou perda do material, assim como a não correção deles, implica em falta ética que compromete a qualidade técnico-científica do processo avaliativo (CFP, 2005).
Do ponto de vista metodológico, na maior parte das pesquisas sobre esta temática, os dados foram coletados pelos próprios pesquisadores e seus colaboradores (Ávila \& Benczik, 2005; Bartholomeu, 2008; Duarte, 1999; Frasson \& Souza, 2002; Grisci, 1991; Hernandez \& Cruz 2001; Lamounier \& Villemor-Amaral, 2006; Rozestraten, 1990; Vieira e cols., 1956). Em função dos problemas aqui assinalados, evidencia-se que a coleta feita a partir das avaliações realizadas por psicólogos peritos em trânsito não é garantia de que os dados serão de boa qualidade para desenvolver pesquisas.

Evidenciou-se que a maior parte dos motoristas não teve registro de infração. Os dados das infrações foram provenientes do órgão de trânsito a partir de um sistema interligado entre os diversos órgãos fiscalizadores de trânsito. Tal procedimento mostrou-se bastante vantajoso pela acessibilidade e eficiência na caracterização dos dados. Estes aspectos também foram constatados por Duarte (1999) ao usar um procedimento semelhante.

Contudo, salienta-se que é necessária cautela na análise de informações onde não se verificam pontos por infrações, pois é possível que algumas delas não tenham sido registradas pela fiscalização, tanto por eventuais falhas no processo, conforme sugerem Marín e Queiroz (2000), quanto pela habilidade do condutor em burlar as leis. Outros estudos, todavia, buscaram identificar os motoristas infratores a partir do auto-relato ou por meio dos cursos de reciclagem de condutores (Ávila \& Benczik, 2005; Frasson \& Souza, 2002; Lamounier \& Villemor-Amaral, 2006). Estes aspectos baseados em auto-relatos também possuem uma série de limitações, pois nem sempre são eficazes e eficientes em possibilitar dados reais e objetivos. Estudos futuros podem tentar clarificar qual seria a medida mais indicada, comparando dados obtidos por meio de auto-relato com medidas obtidas a partir dos órgãos de trânsito, verificando suas relações com os aspectos psicológicos.

O fato de muitos protocolos não serem encontrados reduziu significativamente a quantidade de motoristas pesquisados. Somado a isso, vários testes não foram corrigidos ou analisados na amostra obtida. Conseqüentemente, isso inviabilizou as análises de dados com estatísticas mais robustas. Diante disso, realizaram-se duas análises para tentar encontrar diferenças nas médias dos escores brutos dos testes entre motoristas com e sem registro de infração. Na primeira, os resultados não evidenciaram diferença estatisticamente significativa entre os grupos, corroborando com Duarte (1999), que também não encontrou diferenças entre grupos de infratores e não infratores em relação à atenção concentrada e personalidade. Outros estudos, todavia, sugerem que motoristas infratores possuem algumas características psicológicas distintas daqueles considerados não infratores, especialmente na personalidade (Frasson \& Souza, 2002; Lamounier \& Villemor-Amaral, 2006). Estes resultados não puderam ser aqui testados em relação a este construto.

Na segunda análise, verificou-se que os instrumentos de atenção concentrada e difusa aplicados em 2002 conseguiram diferenciar significativamente os grupos de sujeitos com e sem infrações. Este resultado seria coerente com o 
esperado, à medida que algumas infrações podem se relacionar com a atenção, aspecto importante na tomada de informação, por exemplo, não perceber a sinalização viária e se comportar inadequadamente. Entretanto, recomenda-se bastante cautela nessa interpretação. Em função do emparelhamento da amostra pelas características sócio-demográficas, as médias dos escores brutos foram obtidas com base nos resultados de testes que nem sempre eram os mesmos nos dois momentos. Assim, por exemplo, os escores de um motorista avaliado, em 2002, com o teste de inteligência INV-C e, em 2007, com o R-1, entraram nos cálculos das médias.

O uso de testes diferentes no primeiro e segundo momento de avaliação impossibilitou análises com provas estatísticas mais eficientes, devido a escassez de estudos de validade concorrente, que testa a relação do instrumento com outra medida do mesmo construto. Além disso, por meio desta tentativa, não se teve controle para excluir das análises os testes sem recomendação pelo CFP, não sendo, portanto, medidas confiáveis. Essas limitações, assim como as discrepâncias nos resultados das duas análises acima, sugerem, portanto, que altos ou baixos escores nos instrumentos não são critérios adequados para definir se um motorista cometerá mais ou menos atos infracionais no trânsito, ou se comportará de modo mais arriscado (Bartholomeu, 2008).

As relações entre o número de pontos na $\mathrm{CNH}$ e os escores brutos dos testes foram testadas a partir da correlação. De acordo com os resultados, não foram identificadas correlações estatisticamente significativas entre essas variáveis. Assim, não se pode afirmar, por exemplo, que à medida que a pontuação no escore dos testes aumenta (i.e. maior atenção e maior potencial intelectivo) as infrações tendem a diminuir e vice-versa. Estes resultados são consonantes com os encontrados por Duarte (1999) e Groeger (2003).

A partir deste estudo pode-se dizer que a probabilidade de prever a ocorrência futura de infrações a partir dos resultados dos testes é praticamente inexistente. Os resultados encontrados, todavia, possuem um poder limitado de generalização. Com isso, não se pode afirmar de maneira peremptória que os aspectos psicológicos analisados e as infrações de trânsito não se relacionam. Por um lado, isto se deve em parte à não representatividade da amostra e aos problemas relacionados à qualidade dos dados obtidos, embora se tenha buscado ao máximo trabalhar com informações confiáveis, provenientes dos órgãos oficiais e dos psicólogos capacitados como peritos em trânsito.

Por outro lado, os dados podem indicar que, talvez, em vez de se relacionarem com inteligência ou atenção, as infrações aqui registradas se relacionem mais aos aspectos contextuais da relação recíproca entre o ambiente e o indivíduo no trânsito ou à outras variáveis psicológicas que não foram aqui investigadas. Nessa mesma direção, Bartholomeu (2008), por não haver encontrado fortes evidências entre comportamentos de risco e fatores de personalidade, sugere que a situação de trânsito produz comportamentos inesperados, não associados às características mais estáveis dos sujeitos.

Diferentes tipos de infração (e.g. conduzir o veículo sem portar o documento de habilitação, dirigir com excesso de velocidade, estacionar em local proibido) podem também estar associados a diferentes aspectos psicológicos e comportamentais, requerendo melhor clarificação quanto a suas possíveis distinções e relações futuramente. Esta distinção não foi possível ser investigada neste estudo, tendo em vista que elas foram consideradas de modo geral.

O Brasil é um dos poucos países a exigir de maneira obrigatória a avaliação das condições psicológicas para dirigir. Contudo, nos poucos estudos anteriormente realizados, não foram encontradas contribuições significativas ou sistemáticas relacionando testes psicológicos e segurança no trânsito (Ávila \& Benczik, 2005; Duarte, 1999; Frasson \& Souza, 2002; Grisci, 1991; Lamounier \& Rueda, 2005; Lamounier \& Villemor-Amaral, 2006). Investir nisso parece ser essencial para identificar alguma contribuição da psicologia na promoção da segurança no trânsito, prevenindo especificamente comportamentos infratores. Algumas implicações práticas deste estudo podem ser enunciadas.

Embora não tenha sido o propósito, considera-se que o método usado na pesquisa se mostrou eficaz para detectar alguns problemas no processo de avaliação psicológica no trânsito concernentes à aplicação, correção/análise, expressão dos resultados, armazenamento e recuperação do material psicológico. Nesse sentido, o método pode ser útil aos psicólogos que desejarem verificar a qualidade desses serviços.

Se, por um lado, a literatura sugere problemas relativos aos parâmetros psicométricos dos instrumentos, por exemplo, de validade (Groeger, 2003), esta pesquisa evidenciou que grande parte do problema parece ser relacionado ao próprio psicólogo. Alguns deles já foram apontados por Rozestraten (1982) e Sbardelini (1990). Os psicólogos podem estar adotando estratégias para dar conta do trabalho, tendo em vista o aumento da demanda pela habilitação nos últimos anos, assim como a pressão pela rapidez na entrega dos resultados. Podem indicar também uma formação/capacitação deficitária do profissional que necessita de atualização constante. Tais hipóteses, no entanto, deverão ser mais bem estudadas, tanto pelos conselhos regionais de psicologia em suas atividades de fiscalização, quanto pelas investigações posteriores, que devem buscar as prováveis causas desses problemas para a intervenção adequada.

Para os estudos futuros, estratégias alternativas são recomendadas para serem obtidos dados mais fidedignos, como nas empresas que registram sistematicamente as infrações dos seus motoristas e possuem um processo de avaliação psicológica para acompanhá-los na atividade profissional. Sugere-se analisar outras possíveis variáveis preditoras de infrações (conhecimento das leis de trânsito, dados sócio-demográficos etc.).

Recomenda-se, finalmente, a adoção de um procedimento que acompanhe os condutores nas reavaliações psicológicas e não apenas avalie pontualmente o indivíduo, buscando compreender as razões de possíveis discrepâncias entre os resultados e a implicação disto na segurança. O psicólogo do trânsito tem grande potencial para intervir sistematicamente no trânsito, tendo em vista a quantidade de dados coletados nas clínicas, porém sem uso para pesquisa. 


\section{Referências}

Alchieri, J. C., \& Stroeher, F. (2002). Avaliação psicológica no trânsito: $\mathrm{O}$ estado da arte no Brasil sessenta anos depois. Em R. M. Cruz, J. C. Alchieri \& J. Sardá (Orgs.), Avaliação e Medidas Psicológicas (pp. 234-345). São Paulo: Casa do Psicólogo.

Alchieri, J. C., \& Stroeher, F. (2003). Características do processo de avaliação psicológica para condutores de veículos: Um estudo sobre a tomada de decisão dos psicólogos na utilização de testes psicológicos no Brasil. Revista Iberoamericana de Diagnostico y Evaluación Psicológica, 15(1), 107-119.

Anastasi, A., \& Urbina, S. (2000). Testagem Psicológica. Porto Alegre: Artes Médicas.

Antipoff, D. (1956). Contribuição ao estudo das diferenças individuais no teste de atenção difusa. Arquivos Brasileiros de Psicotécnica, 8(2), 49-60.

Ávila, F. A., \& Benczik, E. B. P. (2005). Transtorno de Déficit de Atenção-Hiperatividade - TDAH: Um estudo do exame psicológico de um motorista infrator. Revista ABRAMET, 22(45), 32-39.

Bartholomeu, D. (2008). Traços de personalidade e comportamentos de risco no trânsito: Um estudo correlacional. Psicologia Argumento, 26(54), 193-206.

Blasco, R. D. (1994). Psychology and road safety. Applied Psychology: An International Review, 43(2), 313-322.

Brasil (2002). Código de trânsito brasileiro. Brasília: Senado Federal.

Campos, F. (1973). A Divisão de Seleção. Arquivos Brasileiros de Psicologia Aplicada, 25(1), 17-49.

Clark, C., \& Engelmann, A. (2001) Avaliação da gravidade e outros parâmetros de infrações de trânsito por motoristas e profissionais: I. Escalonamento a partir da estimativa direta de magnitude. Arquivos Brasileiros de Psicologia, 53(3), 77-93.

Conselho Federal de Psicologia (2003). Resolução CFP $n^{\circ}$ 002/2003. Define e regulamenta o uso, a elaboração e a comercialização de testes psicológicos e revoga a Resolução CFP $n^{\circ}$ 025/2001. Brasília: Autor.

Conselho Federal de Psicologia (2005). Código de Ética Profissional do Psicólogo. Brasília: Autor.

Conselho Federal de Psicologia (2006). Pesquisa Exploratória sobre o Processo de Avaliação Psicológica para a Obtenção da Carteira Nacional de Habilitação. Brasília: Autor.

Conselho Nacional de Trânsito (1998). Resolução $n^{\circ} 80$ de 19 de novembro de 1998, altera os Anexos I e II da Resolução no 51/98-CONTRAN, que dispõe sobre os exames de aptidão fisica e mental e os exames de avaliação psicológica. Brasília: Autor.

Côrtes, G. M. (1952). Colaborações das seleções médica e psicotécnica à prevenção de acidentes de tráfego - a que podem e devem prestar. Arquivos Brasileiros de Psicotécnica, 4(3), 45-51.

Duarte, T. O. (1999). Validade preditiva dos testes atenção concentrada Toulouse-Pierón, Bender e IFP na avaliação do comportamento de motoristas. Dissertação de mestrado, Universidade Federal do Rio Grande do Sul, Porto Alegre.

Frasson, L. M. M., \& Souza, M. A. (2002). Estudo qualitativo da personalidade do motorista infrator através do Rorschach e EDAO. Boletim de Psicologia, 52(117), 141-157.
Grisci, C. L. I. (1991). Relação entre acidentes de trânsito e as variáveis de agressividade, atuação e culpa. PSICO, 21(1), 103-117.

Groeger, J.A. (2003). Testes psicológicos podem predizer habilidade para dirigir? Em R. Risser (Org.), Estudos Sobre a Avaliação Psicológica de Motoristas (pp. 79-95). São Paulo: Casa do Psicólogo.

Groeger, J. A., \& Rothengatter, T. (1998). Traffic psychology and behaviour. Transportation Research Part F, 1, 1-9.

Günther, H. (2009). Conscientizar versus punir: Reflexões sobre comportamento no trânsito. Transporte: Teoria e Aplicação, 1, 5-13. Acessado em http://www.inghum.com/ojs2/index. php/TTAP/index.

Hernandez, J. A. E., \& Cruz, A. B. (2001). O teste de Bender e a seleção de motoristas nos transportes coletivos. Aletheia, 14, 49-61.

Instituto de Pesquisa Econômica Aplicada, Departamento Nacional de Trânsito \& Associação Nacional de Transportes Públicos. (2006). Impactos sociais e econômicos dos acidentes de trânsito nas rodovias brasileiras. Brasília: Autores.

Lamounier, R., \& Rueda, F. J. M. (2005). Avaliação psicológica com o PMK no contexto do trânsito. Psicologia: Pesquisa \& Trânsito, 1(1), 25-32.

Lamounier, R., \& Villemor-Amaral, A. E. (2006). Evidencias de validez para el Rorschach en el contexto de la psicología de transito. Revista Interamericana de Psicología, 40(2), 167-176.

Marín, L., \& Queiroz, M. S. (2000). A atualidade dos acidentes de trânsito na era da velocidade: Uma visão geral. Cadernos de Saúde Pública, 16(1), 7-21.

Méa, C. P. D., \& Ilha, V. D. (2003). Percepção de psicólogos do trânsito sobre a avaliação de condutores. Em M. H. Hoffmann, R. M. Cruz \& J. C. Alchieri (Orgs.), Comportamento humano no trânsito (pp. 263-288). São Paulo: Casa do Psicólogo.

Ministério da Saúde (2007). Mortalidade por acidentes de transporte terrestre no Brasil. Brasília: Autor.

Moyano Díaz, E. (1999). Comportamiento infractor de trásito y atribución causal de accidentes en Chile. Em E. Moyano Díaz (Org.), Psicologia Social y Seguridad de Tránsito (pp. 87-108). Santiago: Editorial Universidad de Santiago.

Nagatsuka, Y. (1989). The current situation of traffic psychology in Japan. Applied Psychology: An International Review, 38(4), 423-442.

Organización Mundial de la Salud (2009). Informe sobre la situación mundial de la seguridad vial: Resumen. Ginebra: Autor.

Pasquali, L. (Org.) (2001). Técnicas de exame psicológico - TEP. Manual. Volume I. São Paulo: Casa do Psicólogo; Brasília: Conselho Federal de Psicologia.

Quintela, G. (1977). A validade do psicotécnico na seleção de motoristas, quando cientificamente aplicado e interpretado o psicodiagnóstico miocinético de Mira y López. Arquivos Brasileiros de Psicologia Aplicada, 29(3), 137-142.

Rothengatter, T. (1997). Psychological aspects of road user behaviour. Applied Psychology: An International Review, 46(3), 223-234.

Rothengatter, T. (2002). Driver's illusions - no more risk. Transportation Research Part F, 5, 249-258. 
Rozestraten, R. J. A. (1982). A opinião de psicólogos brasileiros sobre o exame psicológico para motorista no Brasil [Trabalhos completos]. Em Sociedade Brasileira de Psicologia (Org.), Anais da XII Reunião Anual de Psicologia (p. 105-117). Ribeirão Preto: SBP.

Rozestraten, R. J. A. (1990). O uso e a validade dos testes aplicados aos motoristas - Dados de uma pesquisa [Trabalhos completos]. Em Sociedade Brasileira de Psicologia (Org.), Anais da XX Reunião Anual de Psicologia (p. 471-476). Ribeirão Preto: SBP.

Sbardelini, E. T. B. (1990). O uso e a validade dos testes psicológicos na seleção de motoristas - Formação do psicólogo para atuar em psicotécnico. [Trabalhos completos]. Em Sociedade Brasileira de Psicologia (Org.), Anais da XX Reunião Anual de Psicologia (p. 467-470). Ribeirão Preto: SBP.

Silva, F. H. V. C. (2008). Medida da preditividade de instrumentos psicológicos nas avaliações psicológicas de condutores. Dissertação de Mestrado, Universidade Federal do Rio Grande do Norte, Rio Grande do Norte. Acessado em http://bdtd. bczm.ufrn.br/tedesimplificado/tde_arquivos/1/TDE-2008-1006T054501Z-1467/Publico/FabioHVCS.pdf
Silva, F. H. V. C., \& Alchieri, J. C. (2007). Avaliação psicológica da personalidade de condutores: Uma revisão de literatura. Psico-USF, 12(2), 189-196.

Silva, F. H. V. C., \& Alchieri, J. C. (2008). Revisão das pesquisas brasileiras em avaliação psicológica de habilidades e inteligência de condutores. Estudos de Psicologia (Natal), 13(1), 57-64.

Tortosa, F., \& Montoro, L. (2002). La psicología aplicada a la selección de condutores. Cién años salvando vidas. Psicothema, 14(4), 714-725.

Vieira, M. V. M., Amorim, J. A. \& Carvalho, A. V. (1956). O psicodiagnóstico miocinético na seleção de motoristas. Arquivos Brasileiros de Psicotécnica, 8(1), 53-65.

Recebido em 24.04.09

Primeira decisão editorial em 30.09.09

Versão final em 03.11.09

Aceito em 18.11.09 